Syntax Literate: Jurnal Ilmiah Indonesia p-ISSN: 2541-0849

e-ISSN: 2548-1398

Vol. 6, No. 10, Oktober 2021

\title{
ANALISIS FAKTOR-FAKTOR YANG MEMPENGARUHI KEPUTUSAN PEMBELIAN PRODUK BUSANA GAMIS WANITA PADA TOKO BAJU AA DI PASAR PEMDA CIKAMPEK
}

\section{Hanansa Rais Dabinda}

Program Studi Administrasi Bisnis, Fakultas Komunikasi dan Bisnis, Universitas Telkom Bandung, Indonesia

Email: hanansaraisdabinda@g-mail.com

\begin{abstract}
Abstrak
Penelitian ini dilakukan dengan tujuan untuk mengetahui dan menganalisis faktorfaktor apa saja yang mempengaruhi dan yang paling dominan juga untuk mengetahui faktor baru yang terbentuk dalam pengambilan keputusan konsumen terhadap pembelian produk busana gamis wanita pada Toko Baju AA di Pasar Pemda Cikampek. Penelitian ini menggunakan metode kuantitatif dengan jenis penelitian deskriptif. Pengambilan sampel dilakukan dengan metode nonprobability sampling jenis purposive sampling, dengan jumlah responden sebanyak 100 orang yang merupakan konsumen Toko Baju AA. Teknik pengumpulan data menggunakan angket dan teknik analisis data yang digunakan adalah analisis deskriptif dan analisis faktor. Faktor-faktor yang meliputi penelitian ini adalah keluarga, kelas sosial, kebudayaan, kelompok referensi, motivasi, persepsi, pengalaman belajar, kepribadian, kepercayaan dan sikap, pilihan produk, pilihan merek, pilihan saluran pembelian, dan jumlah pembelian. Berdasarkan hasil pengujian dari 13 dimensi yang diujikan menghasilkan ekstraksi dimana terdapat tiga faktor baru yang terbentuk diantaranya yaitu component I dengan nama faktor keluarga dan variance 33,973\%, component II dengan nama faktor Kepribadian dan variance $14,548 \%$, dan component III dengan nama faktor Pilihan Saluran Pembelian dan variance $9,494 \%$. Pemecahan masalah penelitian telah dijelaskan oleh ketiga faktor yang terbentuk secara keseluruhan dapat menjawab 58,015\% dari masalah dalam penelitian. Sisanya sebesar $41,985 \%$ tidak dijelaskan dalam penelitian karena dianggap tidak berkontribusi secara signifikan. Kesimpulan penelitian ini, berdasarkan hasil pengolahan data terdapat tiga faktor baru yang terbentuk yang dapat mempengaruhi keputusan pembelian busana gamis di Toko Baju AA, dan yang paling mempengaruhi adalah faktor Keluarga, sebaliknya untuk faktor yang tingkat pengaruhnya paling tidak signifikan adalah faktor Pengalaman Belajar.
\end{abstract}

Kata Kunci: keputusan pembelian; faktor-faktor pengaruh; usaha pakaian

\section{Abstract}

Purchasing decisions arise when consumers are interested and want to get the product they have seen. This research was conducted with the aim of knowing and analyzing what factors influence and the most dominant is also to determine the

$\begin{array}{ll}\text { How to cite: } & \text { Dabinda. H.R (2021) Analisis Faktor-Faktor yang Mempengaruhi Keputusan Pembelian Produk Busana } \\ & \text { Gamis Wanita pada Toko Baju AA Di Pasar Pemda Cikampek. Syntax Literate: Jurnal Ilmiah Indonesia, } \\ & \text { 6(10). http://dx.doi.org/10.36418/ Syntax-Literate.v6i10.4265 } \\ & \text { 2548-1398 } \\ \text { E-ISSN: } & \text { Ridwan Institute }\end{array}$


new factors that are formed in consumer decision making on the purchase of women's robe clothing products at the AA clothes shop in Cikampek Regional Government Market. The choice of women's robe clothing as the object of research was due to the large number of sellers in the Cikampek Regional Government Market who chose to sell the women's robe clothes. This research uses quantitative methods with descriptive research type. Sampling was done by using nonprobability sampling method, purposive sampling type, with a total of 100 respondents. The data collection technique used a questionnaire and the data analysis technique used was descriptive analysis and factor analysis. The factors which include this research are family, social class, culture, reference group, motivation, perception, learning experience, personality, beliefs and attitudes, product choice, brand choice, purchase channel choice, and purchase amount. Based on the test results of the 13 dimensions tested to produce extraction where there are three new factors that are formed, namely component I with the name of the family factor and variance $33.973 \%$, component II with the name factor Personality and variance $14.548 \%$, and component III with the name of Purchase Channel Selectionand variance factors 9,494\%. The research problem solving has been explained by the three factors that are formed as a whole can answer $58.015 \%$ of the problems in the study. The remaining $41.985 \%$ is not explained in the study because it is considered not to contribute significantly. The conclusion of this study, based on the results of data processing, there are three new factors that are formed that can influence the decision to buy robe clothing at the AA clothes shop, and the most influencing factor is the family factor, on the other hand, the factor whose level of influence is the least significant is the learning experience factor.

Keywords: purchasing decisions; influence factors; clothing business

Received: 2021-09-20; Accepted: 2021-10-05; Published: 2021-10-20

\section{Pendahuluan}

Seorang konsumen akan berbicara tentang kebaikan suatu perusahaan atau toko jika ia merasa puas dengan pelayanan dan produk yang di dapatkannya (Hayati, 2012), Karena menurut (Amin, 2016), produk bisa menjadi sesuatu untuk memuaskan kebutuhan dan keinginan, Ada beberapa factor yang mempengaruhi pembelian konsumen terhadap suatu produk diantaranya yaitu faktor eksternal dan internal (Ansori, 2019). menurut hasil penelitian,persepsi harga, produk, pelayanan, lokasi dan periklanan terbukti berpengaruh secara signifikan terhadap keputusan konsumen (Khasanah, 2016),selain itu Terdaat 5 peran dalam keputusan pembelian, yaitu; 1. Pemrakarsa (initiator) 2. Pemberi pengaruh (influencer) 3. Pengambil keputusan (decider) 4. Pembeli (buyer) 5. Pemakai (user) (Habli, 2020).

Pakaian memiliki perkembangan model dan bentuk yang terus berubah-ubah dari waktu ke waktu seiring dengan perkembangan zaman. Perkembangan perubahan dari model pakaian dalam setiap tahunnya membuat pakaian memiliki banyak variasi model yang tersebar di masyarakat. Hal ini yang dijadikan kesempatan bagi para pelaku bisnis untuk membuka usaha penjualan pakaian. Toko Baju AA adalah toko baju yang berdiri sejak tahun 2012 dan terletak di Pasar Pemda Cikampek sektor Pakaian Lantai 2 Blok 
EE6 No. 8-9 dan Blok EE 12B No. 1-2. Produk yang ditawarkan oleh Toko Baju AA adalah beragam pakaian wanita yang di dominasi oleh jenis busana gamis. Gamis menurut Kamus Besar Bahasa Indonesia (KBBI) merupakan sejenis baju kurung yang dominan digunakan di Timur Tengah dan Negara-negara Islam lainnya, istilah gamis sendiri berasal dari kata "Khomis" dalam bahasa Arab dan telah diserap ke dalam bahasa Indonesia menjadi "gamis" disertai pergeseran makna. Busana gamis sendiri adalah pakaian muslim wanita (muslimah) dengan model baju yang menyatu bagian atasan dengan bawahannya yang berbentuk lurus, panjang, dan longgar untuk menutupi seluruh badan mulai dari leher hingga ke mata kaki.

Pasar menurut (Stanton, 2015) berpendapat bahwa pengertian pasar adalah sekumpulan orang yang ingin memenuhi kepuasannya dengan menggunakan uang yang dimilikinya untuk berbelanja, serta memiliki kemauan untuk membelanjakan uang tersebut.

Tabel 1

Pertumbuhan Industri Manufaktur Besar dan Sedang Menurut Jenis Industri

\begin{tabular}{lc}
\hline \multicolumn{1}{c}{ Jenis Industri } & $\begin{array}{c}\text { Pertumbuhan Produksi } \\
\text { Year on Year (\%) }\end{array}$ \\
\hline Industri Makanan & 5,02 \\
\hline Industri Bahan Kimia dan Barang dari Bahan Kimia & 7,58 \\
\hline Industri Kendaraan Bermotor, Trailer dan Semi Trailer & $-8,58$ \\
\hline Industri Pengolahan Tembakau & $-1,04$ \\
\hline Industri Kertas dan Barang dari Kertas & 11,24 \\
\hline Industri Karet, Barang dari Karet dan Plastik & $-15,30$ \\
\hline Industri Tekstil & 7,35 \\
\hline Industri Pakaian Jadi & 25,79 \\
\hline Industri Barang Logam, Bukan Mesin dan Peralatannya & $-21,46$ \\
\hline Jasa Reparasi dan Pemasangan Mesin dan Peralatan & $-5,57$
\end{tabular}

Sumber: Badan Pusat Statistik (2019)

Pertumbuhan produksi industri pakaian jadi berhasil memperoleh hasil kinerja yang baik pada tahun 2019. Persentase yang diraih oleh industri pakaian jadi jauh melampaui jenis industri manufaktur besar dan sedang lainnya. Data dari Badan Pusat Statistik menunjukkan industri pakaian jadi mencatatkan pertumbuhan kenaikkan produksi per tahunnya sebesar $25,79 \%$, ini menandakan bahwa pasar atau order pakaian jadi terus meningkat dan masyarakat semakin konsumtif, fasionable, juga meminati hasil dari industri pakaian jadi. 
Tabel 2

Penelitian Terdahulu

\begin{tabular}{|c|c|c|c|c|c|}
\hline $\begin{array}{l}\text { Nama } \\
\text { Penulis }\end{array}$ & $\begin{array}{c}\text { Lokasi } \\
\text { Penelitian }\end{array}$ & $\begin{array}{l}\text { Variabel } \\
\text { dan } \\
\text { Indikator }\end{array}$ & $\begin{array}{c}\text { Teknik } \\
\text { Analisis } \\
\text { Data }\end{array}$ & Hasil Penelitian & Perbedaan \\
\hline $\begin{array}{l}\text { (Eddy \& } \\
\text { Soegiarto, } \\
\text { 2017) }\end{array}$ & $\begin{array}{l}\text { Pasar Pagi } \\
\text { Samarinda }\end{array}$ & $\begin{array}{c}\text { Perilaku } \\
\text { Konsumen, } \\
\text { Pakaian } \\
\text { Wanita }\end{array}$ & $\begin{array}{c}\text { Deskriptif } \\
\text { Kuantitatif, } \\
\text { Angket }\end{array}$ & $\begin{array}{l}\text { Variabel independen } \\
\text { berpengaruh positif } \\
\text { terhadap perilaku } \\
\text { konsumen, } \\
\text { tersebut } \\
\text { mengandung arti } \\
\text { bahwa jika variabel } \\
\text { independen } \\
\text { meningkat (faktor } \\
\text { kebudayaan, sosial, } \\
\text { pribadi, } \\
\text { psikologis) maka } \\
\text { akan meningkat pula } \\
\text { perilaku konsumen } \\
\text { dalam berbelanja } \\
\text { pakaian wanita. }\end{array}$ & $\begin{array}{l}\text { Metode } \\
\text { penelitian }\end{array}$ \\
\hline $\begin{array}{c}\text { (Puspitasari } \\
\& \\
\text { Mubarak, } \\
\text { 2012) }\end{array}$ & $\begin{array}{c}\text { STIE } \\
\text { Kesatuan } \\
\text { Bogor }\end{array}$ & $\begin{array}{l}\text { Perilaku } \\
\text { Pembelian, } \\
\text { Pakaian } \\
\text { Bermerek }\end{array}$ & $\begin{array}{c}\text { Persentase, } \\
\text { Deskriptif } \\
\text { Kuantitatif, } \\
\text { Angket }\end{array}$ & $\begin{array}{lr}\text { Konsumen yang } \\
\text { puas biasanya akan } \\
\text { menyarankan orang } \\
\text { lain untuk membeli } \\
\text { produk r yang } \\
\text { disukainya, namun } \\
\text { hal ini tidak } \\
\text { dijumpai pada objek } \\
\text { penelitian, mereka } \\
\text { menyatakan terserah } \\
\text { dan hanya sedikit } \\
\text { responden yang } \\
\text { menyatakan untuk } \\
\text { membeli merek } \\
\text { yang sama, dan } \\
\text { jawaban ini masih di } \\
\text { bawah 4\%. }\end{array}$ & $\begin{array}{c}\text { Merek } \\
\text { sebagai } \\
\text { variabel }(X)\end{array}$ \\
\hline $\begin{array}{l}\text { (Aprilian, } \\
\text { 2017) }\end{array}$ & $\begin{array}{l}\text { Distro Di } \\
\text { Tembilahan }\end{array}$ & $\begin{array}{l}\text { Pengaruh } \\
\text { Faktor } \\
\text { Pembelian, } \\
\text { Keputusan } \\
\text { Pembelian } \\
\text { Pakaian } \\
\text { Distro }\end{array}$ & $\begin{array}{c}\text { Deskriptif } \\
\text { Kuantitatif, } \\
\text { Angket, } \\
\text { Grafik }\end{array}$ & $\begin{array}{l}\text { Faktor kepribadian } \\
\text { konsumen } \\
\text { berpengaruh secara } \\
\text { positif terhadap } \\
\text { keputusan } \\
\text { pembelian dengan } \\
\text { nilai signifikasi } \\
0,003<0,05 \text {. }\end{array}$ & $\begin{array}{c}\text { Menggunakan } \\
\text { analisis } \\
\text { kolerasi }\end{array}$ \\
\hline $\begin{array}{c}\text { (Kurniasih, } \\
\text { 2018) }\end{array}$ & Banyumas & $\begin{array}{l}\text { Perilaku } \\
\text { Konsumen, } \\
\text { Produk } \\
\text { Batik Tulis }\end{array}$ & $\begin{array}{c}\text { Deskriptif } \\
\text { Kuantitatif, } \\
\text { Angket, } \\
\text { Wawancara, } \\
\text { Purposive } \\
\text { Sampling }\end{array}$ & $\begin{array}{l}\text { Konsumen memiliki } \\
\text { beberapa } \\
\text { pertimbangan antara } \\
\text { lain } \\
\text { mempertimbangkan } \\
\text { motif } \quad 39 \% \text {, }\end{array}$ & $\begin{array}{c}\text { Menggunakan } \\
\text { metode } \\
\text { wawancara }\end{array}$ \\
\hline
\end{tabular}




\begin{tabular}{|c|c|c|c|c|c|}
\hline & & & & $\begin{array}{l}\text { kecocokan dengan } \\
\text { selera } 25 \% \text {, warna } \\
11 \% \text {, harga } 13 \% \text {, } \\
\text { dan kehalusan kain } \\
12 \% \text {. }\end{array}$ & \\
\hline $\begin{array}{c}\text { (Tjahjono, } \\
\text { 2013) }\end{array}$ & $\begin{array}{l}\text { Lingkungan } \\
\text { sosial } \\
\text { pembelian } \\
\text { online } \\
\text { pakaian } \\
\text { wanita }\end{array}$ & $\begin{array}{c}\text { Marketing } \\
\text { Mix, } \\
\text { Lingkungan } \\
\text { Sosial, } \\
\text { Psikologi, } \\
\text { Keputusan } \\
\text { Pembelian, } \\
\text { Pakaian } \\
\text { Wanita }\end{array}$ & $\begin{array}{c}\text { Deskriptif } \\
\text { Kuantitatif, } \\
\text { Angket }\end{array}$ & $\begin{array}{l}\text { Marketing Mix yang } \\
\text { terdiri dari produk, } \\
\text { harga, tempat, dan } \\
\text { promosi } \\
\text { berpengaruh } \\
\text { berpengaruh } \\
\text { terhadap keputusan } \\
\text { pembelian online } \\
\text { pakaian wanita, dan } \\
\text { keputusan membeli } \\
\text { secara online } \\
\text { didahului oleh } \\
\text { pengenalan kebutuhan, } \\
\text { pencarian informasi, } \\
\text { evaluasi alternatif } \\
\text { yang dipengaruhi } \\
\text { faktor internal dan } \\
\text { eksternal. }\end{array}$ & $\begin{array}{c}\text { Melibatkan } \\
\text { marketing } \\
\text { mix dalam } \\
\text { penelitian, } \\
\text { Keputusan } \\
\text { pembelian } \\
\text { sebagai } \\
\text { variabel (Y) }\end{array}$ \\
\hline
\end{tabular}

Pentingnya penelitian ini dilakukan dengan tujuan untuk mengetahui faktor apa saja yang mempengaruhi pengambilan keputusan konsumen dalam membeli produk busana gamis wanita pada Toko Baju AA di Pasar Pemda Cikampek. Penelitian ini juga mencari faktor baru apa saja yang terbentuk dan paling dominan terhadap pengambilan keputusan konsumen dalam membeli produk busana gamis wanita pada Toko Baju AA di Pasar Pemda Cikampek. Berikutnya penelitian ini dapat menjadi bahan referensi dan pembanding bagi penelitian-penelitian selanjutnya yang berkaitan dengan faktor-faktor pengaruh pengambilan keputusan konsumen dalam membeli produk khusunya pakaian. Selanjutnya penelitian ini dapat menjadi pertimbangan dan referensi rujukan yang bermanfaat dalam beberapa hal atau yang lainnya yang dapat sejalan dengan faktorfaktor pengaruh pengambilan keputusan konsumen.

Penulis mencoba mencari faktor-faktor apa saja yang menjadi pertimbangan bagi para konsumen sebelum melakukan pembelian terhadap busana gamis wanita, hingga jenis pakaian yang dijual pada Pasar Pemda Cikampek didominasi oleh penjualan busana gamis wanita. Mengacu pada penjelasan yang telah dijelaskan di atas, berikut pertanyaan penelitian yang penulis ajukan, sebagai bahasan dan untuk dapat dijawab pada penelitian ini: 1) Faktor apa yang mempengaruhi keputusan konsumen dalam membeli produk busana gamis wanita pada Toko Baju AA di Pasar Pemda Cikampek?; 2) Faktor baru apakah yang terbentuk dan yang paling dominan dalam menentukan pengambilan keputusan konsumen ketika membeli produk busana gamis wanita pada Toko Baju AA di Pasar Pemda Cikampek?. 
Berdasarkan latar belakang dan kerangka pemikiran. Hipotesis penelitian diduga faktor budaya, sosial, pribadi, dan psikologis merupakan faktor yang menjadi pertimbangan bagi konsumen dalam membeli produk busana gamis. Faktor dominan yang diduga menjadi pertimbangan bagi konsumen adalah faktor budaya. Penelitian ini bertujuan untuk: 1) Mengetahui faktor apa saja yang mempengaruhi pengambilan keputusan konsumen dalam membeli produk busana gamis wanita pada Toko Baju AA di Pasar Pemda Cikampek. 2) Untuk mengetahui faktor baru apa saja yang terbentuk dan paling dominan terhadap pengambilan keputusan konsumen dalam membeli produk busana gamis wanita pada Toko Baju AA di Pasar Pemda Cikampek.

\section{Metode Penelitian}

Metode penelitian menggunakan deskriptif kuantitatif, proses penelitian terdiri dari dua tahap analisis (Cresswell, 2017). Analisis pertama adalah analisis deskriptif yang digunakan untuk mengidentifikasi karakteristik konsumen dan menganalisis proses keputusan pembeliannya. Analisis kedua adalah analisis faktor untuk mengidentifikasi faktor-faktor yang mempengaruhi pembelian busana gamis pada Toko Baju AA di Pasar Pemda Cikampek, setelah dilakukan analisis faktor terbentuk tiga faktor baru dengan faktor terkuat adalah faktor keluarga. Secara ringkas kerangka pemikiran dapat dilihat pada gambar 1 .

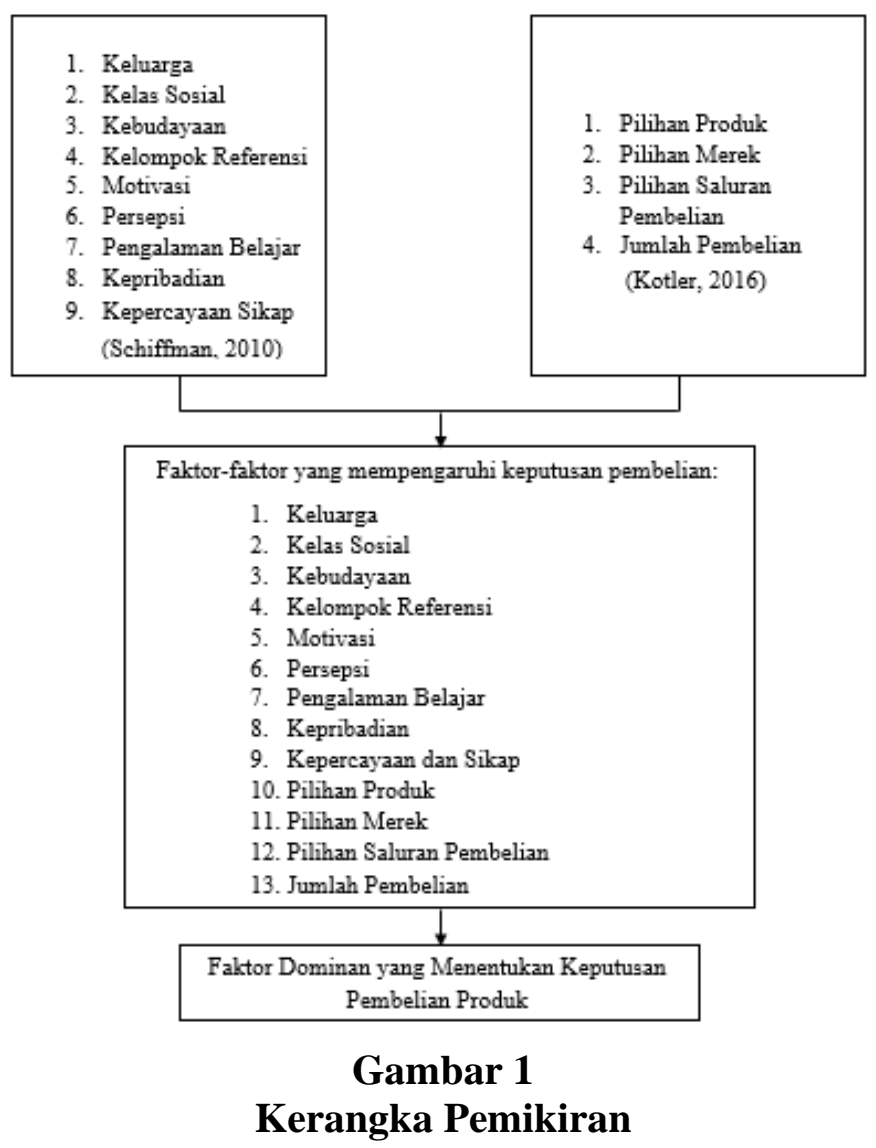


Jenis data yang digunakan pada penelitian ini adalah data primer dan juga data sekunder. Sampel pada penelitian ini adalah konsumen busana gamis Toko Baju AA di Pasar Pemda Cikampek. Metode pengambilan sampel dilakukan dengan metode nonprobability sampling jenis purposive sampling yaitu bentuk pengambilan sampel berdasarkan kriteria tertentu agar data yang diperoleh lebih representatif. Jumlah sampel dalam penelitian ini dihitung dengan menggunakan rumus Bernoulli dengan hasil pembulatan sebanyak 100 responden.

$$
\begin{gathered}
n \leq \frac{Z \cdot \frac{\alpha}{2} \cdot p \cdot q}{(e)^{2}} \\
n \geq \frac{[1,96]^{2} \cdot 0,5 \cdot 0,5}{0,1^{2}} \\
n \geq \frac{[3,8416] \cdot 0,25}{0,01} \\
n \geq 96,04
\end{gathered}
$$

Di mana:

$\mathrm{n} \quad=$ Jumlah sampel minimum

$\mathrm{Z} \quad=$ Kuadrat dari confidenceinterval

$\frac{\sigma}{2^{2}} \quad=$ Tingkat kepercayaan

$\mathrm{p} \quad=$ Prosorsi jumlah kuesioner yang valid

$\mathrm{q}=$ Proporsi jumlah kuesioner yang tidak valid

$\mathrm{e} \quad=$ Toleransi kesalahan

Sasaran penelitian adalah konsumen yang sudah pernah datang dan berbelanja busana gamis di Toko Baju AA pada Pasar Pemda Cikampek.

\section{Hasil dan Pembahasan}

\section{A. Gambaran Umum Toko Baju AA dan Pasar Pemda Cikampek}

Toko Baju AA adalah toko baju yang berdiri sejak tahun 2012 dan terletak di Pasar Pemda Cikampek sektor Pakaian Lantai 2 Blok EE6 No. 8-9 dan Blok EE 12B No. 1-2. Produk yang ditawarkan oleh Toko Baju AA adalah beragam pakaian wanita yang di dominasi oleh jenis busana gamis. Pasar Pemda Cikampek menjadi salah satu pusat kegiatan perekonomian yang terbesar di Kabupaten Karawang khususnya di Kota Cikampek selain dari pasar lainnya seperti Pasar Kosambi dan Pasar Baru Karawang. Pasar Pemda Cikampek pada bagian penjualan pakaian memiliki sebanyak 640 kios yang menjual berbagai macam jenis pakaian yang di dominasi oleh penjualan jenis pakaian busana gamis wanita sebanyak 157 kios. 


\section{B. Karakteristik Konsumen}

Produk fashion yang biasa dibeli
100 tanggapan

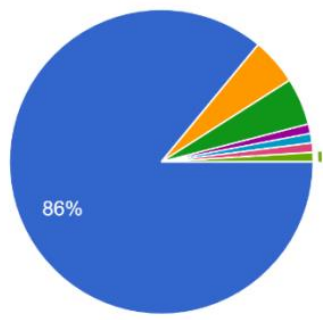

Gambar 2

Produk Fashion yang Biasa Dibeli

Sumber: Data Primer yang Diolah (2021)

Diketahui bahwa dari 100 responden yang telah dibagikan kuesioner menunjukkan bahwa responden banyak yang terbiasa melakukan pembelian produk fashion jenis pakaian dengan pesentase sebesar $86 \%$, untuk yang terbiasa membeli produk fashion jenis sandal/sepatu sebanyak 5\%, untuk yang terbiasa membeli produk fashion jenis tas sebanyak 5\%, untuk yang terbiasa membeli produk fashion jenis aksesoris sebanyak 1\%, sedangkan untuk 3\% sisanya terbiasa terbiasa membeli produk fashion jenis lainnya. Hal ini disebabkan karena terkait dengan industri pakaian jadi yang memang selalu mengalami peningkatan pada setiap tahunnya, seiring dengan banyaknya konsumen yang terbiasa melakukan pembelian produk fashion jenis pakaian.

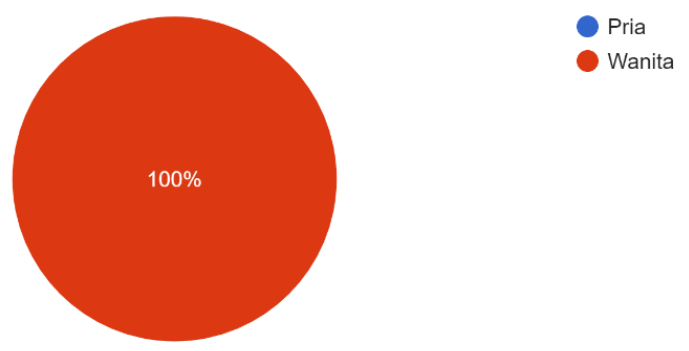

\section{Gambar 3}

Jenis Kelamin

Sumber: Data Primer yang Diolah (2021)

Diketahui bahwa dari 100 responden yang telah dibagikan kuesioner menunjukkan bahwa responden yang berjenis kelamin perempuan sebanyak $100 \%$ 
atau 100 responden, sedangkan yang berjenis kelamin laki-laki sebanyak $0 \%$ atau 0 responden. Hal ini disebabkan karena konsumen yang terbiasa membeli busana gamis wanita di Toko Baju AA adalah perempuan. Informasi tersebut menunjukkan bahwa sebagian besar responden pada penelitian ini di dominasi oleh perempuan.

$$
\begin{aligned}
& \text { Usia } \\
& 100 \text { tanggapan }
\end{aligned}
$$
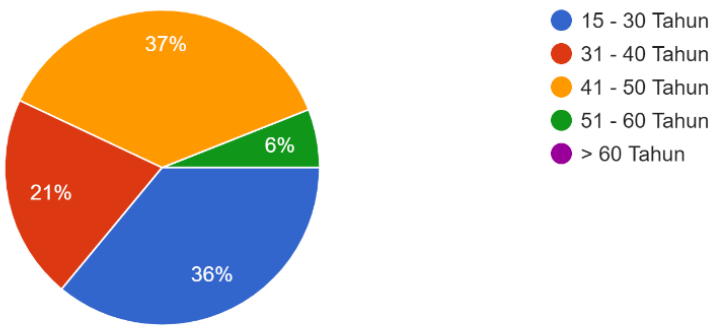

\section{Gambar 4}

Usia

Sumber: Data Primer yang Diolah (2021)

Untuk usia dari 100 responden yang telah dibagikan kuesioner menunjukkan bahwa responden berdasarkan usia cukup merata pada range 15 - 50 tahun, dimana yang berusia 15 - 30 tahun sebanyak $36 \%$ atau 36 responden, untuk usia $31-40$ tahun sebanyak $21 \%$ atau 21 responden, untuk usia 41 - 50 tahun sebanyak $37 \%$ atau 37 responden, dan untuk usia $51-60$ tahun sebanyak $6 \%$ atau 7 responden. Hal ini disebabkan karena banyaknya konsumen busana gamis wanita di Toko Baju AA adalah perempuan dewasa.

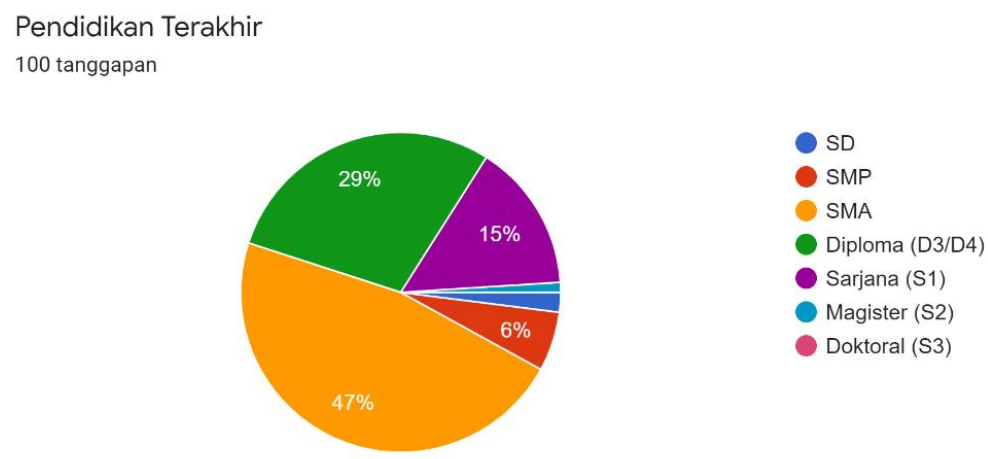

\section{Gambar 5 \\ Pendidikan Terakhir}

Sumber: Data Primer yang Diolah (2021)

Pendidikan terakhir dari 100 responden yang telah dibagikan kuesioner menunjukkan bahwa responden berdasarkan pendidikan terakhir di dominasi oleh 
lulusan SMA sebanyak $47 \%$ atau 47 responden. Hal ini dikarenakan banyaknya konsumen Toko Baju AA adalah perempuan dewasa yang sebagian besar pendidikan terakhirnya adalah SMA.

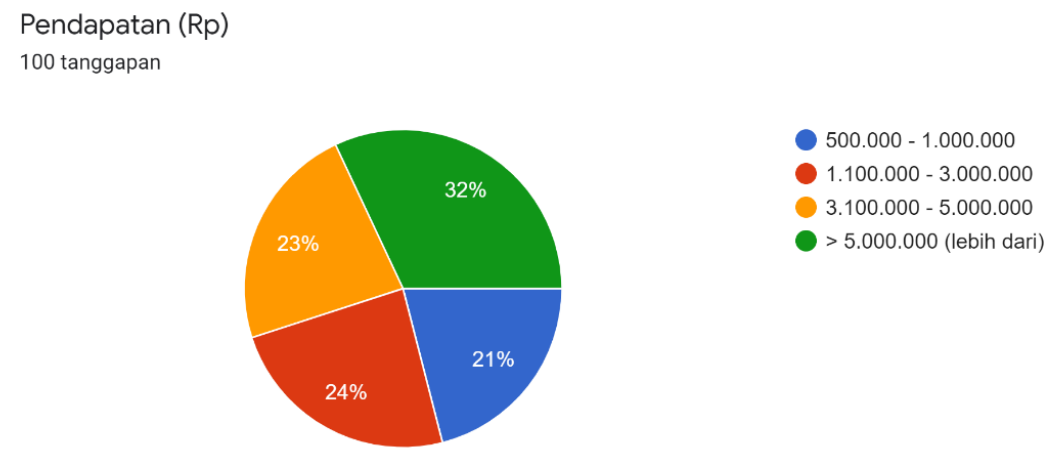

\section{Gambar 6 \\ Pendapatan}

Sumber: Data Primer yang Diolah (2021)

Untuk pendapatan dari 100 responden yang telah dibagikan kuesioner menunjukkan bahwa responden berdasarkan pendapatannya cukup merata di setiap kategori range pendapatan per-bulannya dimana pendapatan Rp500.000 Rp1.000.000 sebanyak 21\% atau 21 responden, untuk pendapatan Rp1.100.000 - Rp 3.000 .000 sebanyak 24\% atau 24 responden, untuk pendapatan Rp3.100.000 Rp5.000.000 sebanyak 23\% atau 23 responden, dan untuk pendapatan > Rp5.000.000 sebanyak 32\% atau 32 responden. Hal ini dikarenakan konsumen busana gamis wanita yang datang ke Toko Baju AA berasal dari beragam latar belakang ekonomi yang berbeda-beda.
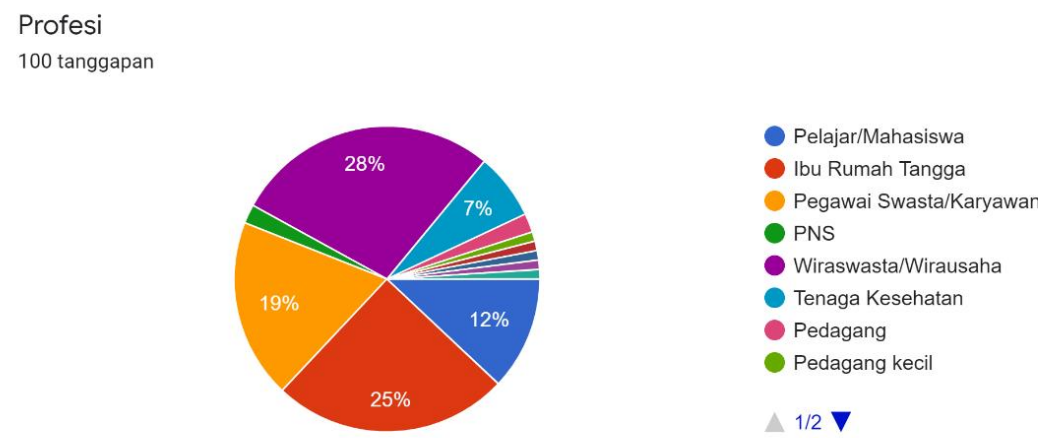

\section{Gambar 7 \\ Profesi}

Sumber: Data Primer yang Diolah (2021)

Untuk profesi dari 100 responden yang telah dibagikan kuesioner menunjukkan bahwa responden berdasarkan profesinya cukup beragam namun di 
dominasi oleh ibu rumah tangga sebanyak $25 \%$ atau 25 responden, lalu wiraswasta sebanyak 28\% atau 28 responden, dan pegawai swasta sebanyak $19 \%$ atau 19 responden. Hal ini dikarenakan lokasi Toko Baju AA yang berada di Pasar Pemda Cikampek yang memungkinkan banyaknya ibu rumah tangga yang berkunjung untuk berbelanja, dan para wiraswasta sendiri yang banyak memiliki usaha di area Pasar Pemda Cikampek.

\section{Perilaku Konsumen}

Pengertian perilaku konsumen menurut Engel dalam (Sangadji, 2018) adalah tindakan yang terlibat secara langsung dalam proses pemerolehan, pengonsumsian, dan penghabisan produk/jasa, termasuk proses mendahului dan menyusul tindakan. Perilaku konsumen sebagai perilaku yang diperlihatkan oleh seorang konsumen untuk mencari, membeli, menggunakan, mengevaluasi, dan menghabiskan produk dan jasa yang mereka harapkan akan dapat memuaskan kebutuhan mereka. Faktorfaktor yang mempengaruhi perilaku konsumen menurut (Schiffman, 2010) diantaranya adalah: (1) keluarga, (2) kelas sosial, (3) kebudayaan, (4) kelompok referensi, (5) motivasi, (6) persepsi, (7) pengalaman belajar, (8) kepribadian, (9) kepercayaan dan sikap.

Jumlah responden pada penelitian ini sebanyak 100 orang, dan nilai pengukuran skala terbesar adalah 5, sedangkan untuk yang terkecil adalah 1, sehingga diperoleh jumlah kumulatif terbesar $100 \times 5=500$ dan jumlah kumulatif terkecil $100 \times 1=100$. Adapun nilai persentase terbesar adalah $(500: 500) \times 100 \%=$ $100 \%$, sedangkan nilai persentase terkecil $(100: 500) \times 100 \%=20 \%$. Nilai rentang $100 \%-20 \%=80 \%$, jika dibagi 5 skala pengukuran maka didapat interval persentase sebesar $16 \%$. Berdasarkan perhitungan tersebut, maka dapat diperoleh klasifikasi kriteria interpretasi skor seperti berikut ini:

Tabel 3

Kriteria Interpretasi Skor

\begin{tabular}{ccc}
\hline No & Persentase Penilaian & Kategori \\
\hline 1 & $20 \%-36 \%$ & Sangat Tidak Baik \\
\hline 2 & $>36 \%-52 \%$ & Tidak Baik \\
\hline 3 & $>52 \%-68 \%$ & Cukup \\
\hline 4 & $>68 \%-84 \%$ & Baik \\
\hline 5 & $>84 \%-100 \%$ & Sangat Baik \\
\hline
\end{tabular}

Perilaku konsumen berdasarkan hasil penelitian untuk faktor keluarga berada pada kategori "Cukup" dengan persentase sebesar 63\%, untuk faktor kelas sosial berada pada kategori "Cukup" dengan persentase sebesar 67\%, untuk faktor kebudayaan berada pada kategori "Baik" dengan persentase sebesar $81 \%$, untuk faktor kelompok referensi berada pada kategori "Baik" dengan persentase sebesar $78 \%$, untuk faktor motivasi berada pada kategori "Sangat Baik" dengan persentase sebesar $89 \%$, untuk faktor persepsi berada pada kategori "Sangat Baik" dengan persentase sebesar $84 \%$, untuk faktor pengalaman belajar berada pada kategori 
"Sangat Baik" dengan persentase sebesar 84\%, untuk faktor kepribadian berada pada kategori "Baik" dengan persentase sebesar 79\%, untuk faktor kepercayaan dan sikap berada pada kategori "Baik" dengan persentase sebesar 81\%. Berdasarkan hasil interpretasi skor di atas menunjukkan bahwa faktor-faktor yang mempengaruhi perilaku konsumen sesuai dengan hasil penelitian semuanya dapat dikatakan berpengaruh pada konsumen melihat pada angka persentase di setiap faktor.

\section{Faktor-Faktor Yang Mempenaruhi Keputusan Pembelian Konsumen}

Pengertian keputusan pembelian menurut (Kotler, 2016) adalah sebuah tahap dalam dari sebuah proses pengambilan keputusan pembeli di mana konsumen benarbenar melakukan pembelian. Menurut (Schiffman, 2010) keputusan pembelian didefinisikan sebagai sebuah pilihan dari dua atau lebih alternatif pilihan. Keputusan pembelian adalah sebuah pemikiran dimana seorang individu mengevaluasi berbagai pilihan sebelum menjatuhkan pilihan pada suatu produk atau jasa dari sekian banyak pilihan yang ditawarkan. Menurut (Kotler, Philip dan Keller, 2016) keputusan pembelian memiliki dimensi sebagai berikut: (1) pilihan produk, (2) pilihan merek, (3) pilihan saluran pembelian (4) jumlah pembelian.

Berdasarkan perhitungan seperti yang ditampilkan pada tabel 3 di atas keputusan pembelian konsumen berdasarkan hasil penelitian untuk faktor pilihan produk berada pada kategori "Baik" dengan persentase sebesar 77\%, untuk faktor pilihan merek berada pada kategori "Cukup" dengan persentase sebesar 58\%, untuk faktor pilihan saluran pembelian berada pada kategori "Baik" dengan persentase sebesar $82 \%$, untuk faktor jumlah pembelian berada pada kategori "Cukup" dengan persentase sebesar $60 \%$. Berdasarkan hasil interpretasi skor di atas menunjukkan bahwa dimensi keputusan pembelian yang mempengaruhi perilaku konsumen sesuai dengan hasil penelitian semuanya dapat dikatakan berpengaruh pada konsumen melihat pada angka persentase di setiap dimensi.

\section{E. Analisis Faktor}

Berikut adalah tahapan-tahapan dalam melakukan analasis faktor menurut (Soeroso, 2018) adalah sebagai berikut: (1) merumuskan masalah, (2) membentuk matriks korelasi (KMO/Kaiser-Mayer-Olkin dan Bartletts Test of Sphericity), (3) proses factoring dan rotasi (correlation matrix, unrotated factor solution, communalities, total variance explained, scree plot, component matrix, rotated component matrix), (4) membuat interpretasi hasil rotasi.

Bentuk matriks korelasi total dimensi faktor yang digunakan dalam penelitian ini adalah sebanyak 13 dimensi, yang menjadi 43 pernyataan dalam kuesioner. Seluruh dimensi yang diteliti di input ke dalam software SPSS dan diikuti data yang diperoleh KMO and Bartlett's Test Sphericity yang digunakan untuk dapat melihat terkait layak tidaknya analisis faktor yang dilakukan dalam penelitian ini, dan setelah itu menggunakan pengujian Anti Image Matrices. Setelah dilakukan uji KMO and Bartlett's Test Sphericity bahwa 100 responden memiliki ukuran kecukupan sampel (KMO Measure of Sampling Adequacy) pada penelitian ini 
adalah 0,814 dan nilai signifikan (Bartlett's Test of Sphericity) 0,00 yang artinya dapat dipercaya $100 \%$ bahwa antar dimensi terdapat korelasi.

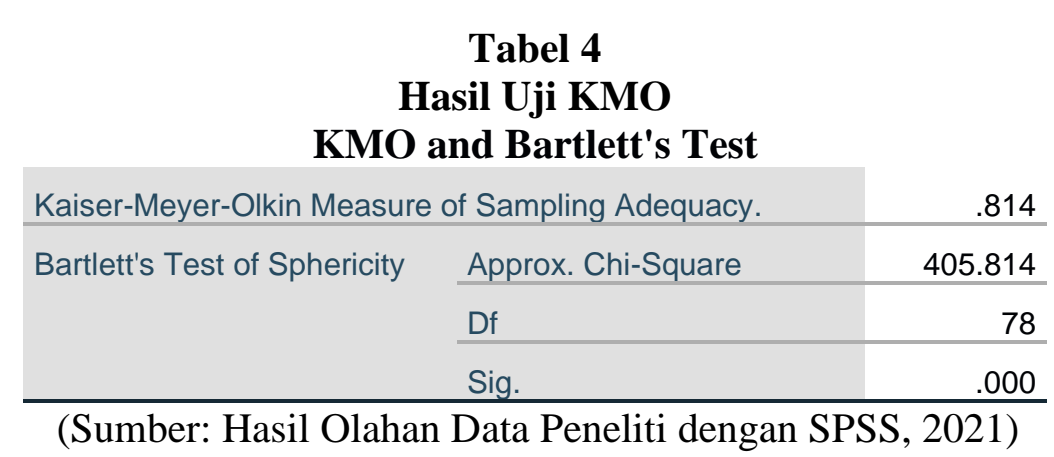

Jika nilai KMO Measure of Sampling Adequacy > 0,50 dan nilai Bartlett's Test of Sphericity < 0,05 maka teknik analisis faktor dapat dilanjutkan. Mengacu pada nilai ketepatan KMO Measure of Sampling Adequacy dan Bartlett's Test of Sphericity maka analisis faktor dalam penelitian ini dapat dilanjutkan.

Tabel 5

Hasil Uji Anti Image Matrices

\begin{tabular}{clc}
\hline No. & \multicolumn{1}{c}{ Faktor-Faktor } & Nilai MSA \\
\hline 1. & Motivasi & 0,647 \\
\hline 2. & Persepsi & 0,740 \\
\hline 3. & Pengalaman Belajar & 0,834 \\
\hline 4. & Kepribadian & 0,834 \\
\hline 5. & Kepercayaan dan Sikap & 0,846 \\
\hline 6. & Keluarga & 0,814 \\
\hline 7. & Kelas Sosial & 0,849 \\
\hline 8. & Kebudayaan & 0,832 \\
\hline 9. & Kelompok Referensi & 0,851 \\
\hline 10. & Pilihan Produk & 0,888 \\
\hline 11. & Pilihan Merek & 0,860 \\
\hline 12. & Pilihan Saluran Pembelian & 0,778 \\
\hline 13. & Jumlah Pembelian & 0,755 \\
\hline & Sumber: Hasil Olahan Data Peneliti dengan SPSS, 2021$)$
\end{tabular}

(Sumber: Hasil Olahan Data Peneliti dengan SPSS, 2021)

Tahap berikutnya adalah Anti Image Matrices yang berguna untuk menentukan data yang layak pakai dalam proses analisis faktor. Pada bagian Anti-Image Correlation di tabel Anti Image Matrices terdapat kode huruf (a) yang artinya tanda untuk Measure of Sampling Adequacy (MSA). Persyaratan yang harus terpenuhi dalam analisis faktor adalah nilai MSA > 0,50. Setelah dilakukan pengujian diketahui bahwa nilai MSA untuk semua dimensi > 0,50 maka semua variabel layak untuk dilakukan analisis faktor.

Proses factoring dan rotasi dilakukan dengan tujuan untuk mengetahui faktorfaktor baru yang terbentuk. Menurut (Soeroso, 2018) proses factoring dan rotasi 
juga untuk menentukan ke dalam faktor baru mana variabel tersebut akan masuk dan apakah layak dimasukkan dalam faktor yang satu atau faktor yang lain. Tahapan yang dilakukan diantaranya menggunakan pengujian communalities, total variance explained, scree plot, component matrix, dan rotated component matrix.

Tabel 6

Hasil Uji communalities

Communalities

\begin{tabular}{|c|c|c|}
\hline & Initial & $\begin{array}{c}\text { Extractio } \\
\mathrm{n}\end{array}$ \\
\hline Motivasi & 1.000 & .726 \\
\hline Persepsi & 1.000 & .603 \\
\hline Pengalaman Belajar & 1.000 & .525 \\
\hline Kepribadian & 1.000 & .683 \\
\hline Kepercayaan dan Sikap & 1.000 & .573 \\
\hline Keluarga & 1.000 & .683 \\
\hline Kelas Sosial & 1.000 & .542 \\
\hline Kebudayaan & 1.000 & .559 \\
\hline Kelompok Referensi & 1.000 & .561 \\
\hline Pilihan Produk & 1.000 & .535 \\
\hline Pilihan Merek & 1.000 & .575 \\
\hline Pilihan Saluran Pembelian & 1.000 & .625 \\
\hline Jumlah Pembelian & 1.000 & .552 \\
\hline
\end{tabular}

Extraction Method: Principal Component

Analysis.

(Sumber: Hasil Olahan Data Peneliti dengan SPSS, 2021)

Communalities menunjukkan nilai variabel yang diteliti apakah mampu untuk menjelaskan faktor atau tidak. Variabel dianggap mampu untuk menjelaskan faktor jika nilai Extraction > 0,50. Berdasarkan output di atas, dimana semua nilai Extraction untuk semua variabel adalah > 0,50 maka semua variabel dapat dipakai untuk menjelaskan faktor. Nilai Extraction juga menggambarkan semakin besar nilainya maka semakin erat hubungan antara variabel yang ada dengan variabel yang baru terbentuk. 
Tabel 7

Hasil Uji Total Variance Explained

Total Variance Explained

\begin{tabular}{|c|c|c|c|c|c|c|}
\hline Compon & & Initial Eigenvalu & & Extractic & n Sums of Squar & ed Loadings \\
\hline ent & Total & $\%$ of Variance & Cumulative $\%$ & Total & $\%$ of Variance & Cumulative $\%$ \\
\hline 1 & 4.416 & 33.973 & 33.973 & 4.416 & 33.973 & 33.973 \\
\hline 2 & 1.891 & 14.548 & 48.521 & 1.891 & 14.548 & 48.521 \\
\hline 3 & 1.234 & 9.494 & 58.015 & 1.234 & 9.494 & 58.015 \\
\hline 4 & .932 & 7.169 & 65.184 & & & \\
\hline 5 & .761 & 5.853 & 71.037 & & & \\
\hline 6 & .670 & 5.151 & 76.188 & & & \\
\hline 7 & .608 & 4.681 & 80.868 & & & \\
\hline 8 & .553 & 4.252 & 85.121 & & & \\
\hline 9 & .492 & 3.785 & 88.906 & & & \\
\hline 10 & .432 & 3.320 & 92.225 & & & \\
\hline 11 & .372 & 2.863 & 95.088 & & & \\
\hline 12 & .334 & 2.569 & 97.657 & & & \\
\hline 13 & .305 & 2.343 & 100.000 & & & \\
\hline
\end{tabular}

Extraction Method: Principal Component Analysis.

(Sumber: Hasil Olahan Data Peneliti dengan SPSS, 2021)

Total Variance Explained menunjukkan nilai masing-masing variabel yang dianalisis. Faktor yang terbentuk memiliki nilai Initial Eigenvalues > 1. Dapat dilihat bahwa terdapat tiga faktor yang terbentuk yaitu component 1 dengan total 4,416 dan variance 33,973\%, component 2 dengan total 1,891 dan variance $14,548 \%$, dan component 3 dengan total 1,234 dan variance 9,494\%. Pada component berikutnya totalnya $<1$ maka proses factoring berhenti sampai component tiga. Berdasarkan Tabel 5. dimana terdapat 13 faktor yang dilakukan analisis, dengan masing-masing faktor memiliki varian $=1$. Total varian yang dihasilkan adalah $13 \times 1=13$. Jika 13 faktor tersebut diringkas ke dalam faktor yang telah terbentuk, maka perhitungannya sebagai berikut: 1) Component $1=4,416 / 13 \times$ $100 \%=33,973 \%, 2)$ Component $2=1,891 / 13 \times 100 \%=14,548 \%, 3)$ Component 3 $=1,234 / 13 \times 100 \%=9,494 \%$ dari perhitungan tersebut total dari ketiga faktor terbentuk akan dapat menjelaskan 58,015\% dari keseluruhan faktor. 


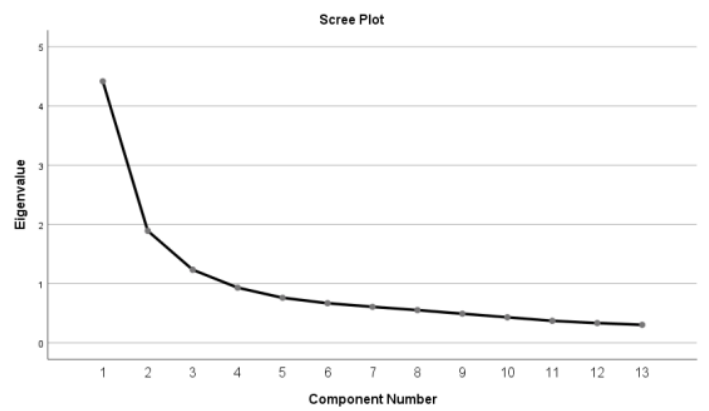

\section{Gambar 8}

Scree Plot

(Sumber: Hasil Olahan Data Peneliti dengan SPSS, 2021)

Gambar 2. menunjukkan jumlah faktor yang terbentuk dengan cara melihat nilai titik component yang memiliki nilai Eigenvalues $>1$. Hal ini menunjukkan bahwa yang mendominasi untuk dapat meringkas ke 13 faktor tersebut yaitu component 1 , component 2 , dan component 3 yang berada di atas angka satu sumbu Y eigenvalues. Hasil dari Sree Plot selalu sama dengan hasil Total Variance Explained untuk pembentukan faktor karena selain memaknai secara statistik tetapi juga dapat melihat dengan gambar untuk saling melengkapi.

Tabel 8

Hasil Uji component matrix Component Matrix ${ }^{\mathrm{a}}$

\begin{tabular}{|c|c|c|c|}
\hline & \multicolumn{3}{|c|}{ Component } \\
\hline & 1 & 2 & 3 \\
\hline Motivasi & .411 & .573 & .479 \\
\hline Persepsi & .478 & .601 & -.113 \\
\hline Pengalaman Belajar & .521 & .385 & .069 \\
\hline Kepribadian & .670 & .420 & -.240 \\
\hline Kepercayaan dan Sikap & .667 & .259 & -.247 \\
\hline Keluarga & .632 & -.440 & -.300 \\
\hline Kelas Sosial & .608 & -.411 & -.055 \\
\hline Kebudayaan & .606 & .033 & -.437 \\
\hline Kelompok Referensi & .608 & -.225 & -.201 \\
\hline Pilihan Produk & 690 & -.080 & .229 \\
\hline Pilihan Merek & .600 & -.337 & .318 \\
\hline Pilihan Saluran Pembelian & .523 & -.039 & .591 \\
\hline Jumlah Pembelian & .488 & -.523 & .203 \\
\hline
\end{tabular}

Extraction Method: Principal Component Analysis.

a. 3 components extracted.

(Sumber: Hasil Olahan Data Peneliti dengan SPSS, 2021) 
Berdasarkan Tabel 6. diketahui terbentuk 3 faktor baru. Component Matrix ini menunjukkan nilai korelasi antara masing-masing variabel dengan faktor yang terbentuk. Dapat dilihat pada item 1 yaitu Motivasi akan masuk ke dalam component 2, karena korelasi item 1 terhadap component 2 sebesar 0,573 lebih besar daripada korelasi item 1 terhadap component 1 yang hanya sebesar 0,411 dan terhadap component 3 yang hanya sebesar 0,479. Semakin besar korelasi item dengan component, maka semakin besar pula kesempatan item tersebut untuk diwakili oleh salah satu component, sedangkan tanda positif dan negatif hanya menunjukkan arah dan hanya berpengaruh pada arti angka itu sendiri.

Tabel 9

Hasil Uji rotated component matrix Rotated Component Matrix ${ }^{a}$

\begin{tabular}{|c|c|c|c|}
\hline & \multicolumn{3}{|c|}{ Component } \\
\hline & 1 & 2 & 3 \\
\hline Motivasi & -.291 & .563 & .570 \\
\hline Persepsi & -.035 & .772 & .073 \\
\hline Pengalaman Belajar & .063 & .590 & .270 \\
\hline Kepribadian & .258 & .783 & .062 \\
\hline Kepercayaan dan Sikap & .363 & .661 & .065 \\
\hline Keluarga & .815 & .123 & .054 \\
\hline Kelas Sosial & .685 & .070 & .259 \\
\hline Kebudayaan & .545 & .499 & -.114 \\
\hline Kelompok Referensi & .622 & .248 & .115 \\
\hline Pilihan Produk & .413 & .301 & .523 \\
\hline Pilihan Merek & .487 & .030 & .581 \\
\hline $\begin{array}{l}\text { Pilihan Saluran } \\
\text { Pembelian }\end{array}$ & .137 & .141 & .765 \\
\hline Jumlah Pembelian & .579 & -.151 & .441 \\
\hline \multicolumn{4}{|c|}{$\begin{array}{l}\text { Extraction Method: Principal Component Analysis. } \\
\text { Rotation Method: Varimax with Kaiser Normalization. } \\
\text { a. Rotation converged in } 26 \text { iterations. } \\
\text { (Sumber: Hasil Olahan Data Peneliti dengan SPSS, 2021) }\end{array}$} \\
\hline
\end{tabular}

Rotasi dilakukan dengan cara memutar ketiga component yang belum dirotasi. Cara merotasinya dengan orthogonal, tujuannya adalah untuk mempertajam factor loading setiap variabel untuk ketiga component. Setelah dilakukan rotasi faktor untuk memastikan suatu variabel masuk dalam kelompok faktor yang mana, maka dapat ditentukan dengan melihat nilai korelasi terbesar antara variabel dengan faktor (component) yang terbentuk. Kelima faktor yang terdapat dalam Tabel 7. ini termasuk ke dalam Komponen Faktor I. Hal ini disebabkan karena kelima faktor (keluarga, kelas sosial, kebudayaan, kelompok referensi, jumlah pembelian) 
memiliki korelasi yang kuat pada component 1 . Komponen Faktor I sendiri memiliki nilai variance terbesar yaitu 33,973\% sehingga faktor ini menjadi yang paling dominan dalam mempengaruhi keputusan konsumen dalam melakukan pembelian busana gamis wanita di Toko Baju AA. Keempat faktor (persepsi, pengalaman belajar, kepribadian, kepercayaan dan sikap) yang terdapat dalam Tabel 7. ini termasuk ke dalam Komponen Faktor II. Hal ini disebabkan karena keempat faktor memiliki korelasi yang kuat pada component 2. Komponen Faktor II sendiri memiliki nilai variance sebesar $14,548 \%$ terbesar kedua. Keempat faktor yang terdapat dalam Tabel 7. ini termasuk ke dalam Komponen Faktor III (motivasi, pilihan produk, pilihan merek, pilihan saluran pembelian). Hal ini disebabkan karena keempat faktor memiliki korelasi yang kuat pada component 3. Komponen Faktor II sendiri memiliki nilai variance sebesar 9,494\%.

Interpretasi hasil rotasi pada proses analisis faktor yang telah dijelaskan sebelumnya, dapat ditarik sebuah kesimpulan bahwa terdapat tiga faktor yang terbentuk menjadi sebuah bahan pertimbangan konsumen dalam membeli busana gamis wanita di Toko Baju AA.

Tabel 10

Faktor Yang Terbentuk

\begin{tabular}{cllc}
\hline Faktor & \multicolumn{2}{c}{ Variabel Terbentuk } & Loading Factor \\
\hline \multirow{3}{*}{1} & Keluarga & Item 6 & 0,815 \\
\cline { 2 - 4 } & Kelas Sosial & Item 7 & 0,685 \\
\cline { 2 - 4 } & Kelompok Referensi & Item 9 & 0,622 \\
\cline { 2 - 4 } & Jumlah Pembelian & Item 13 & 0,579 \\
\cline { 2 - 4 } & Kebudayaan & Item 8 & 0,545 \\
\hline \multirow{3}{*}{2} & Kepribadian & Item 4 & 0,783 \\
\cline { 2 - 4 } & Persepsi & Item 2 & 0,772 \\
\cline { 2 - 4 } & Kepercayaan dan Sikap & Item 5 & 0,661 \\
\hline \multirow{3}{*}{3} & Pengalaman Belajar & Item 3 & 0,590 \\
\cline { 2 - 4 } & Pilihan Saluran Pembelian & Item 12 & 0,765 \\
\cline { 2 - 4 } & Pilihan Merek & Item 11 & 0,581 \\
\cline { 2 - 4 } & Motivasi & Item 1 & 0,570 \\
\cline { 2 - 4 } & Pilihan Produk & Item 10 & 0,523 \\
\hline
\end{tabular}

(Sumber: Hasil Olahan Data Peneliti dengan SPSS, 2021)

Nilai loading yang terdapat dalam masing-masing komponen adalah nilai-nilai yang menunjukkan besarnya kontribusi dari masing-masing item terhadap masingmasing komponen yang dipertahankan sebagai suatu komponen-komponen pengganti yang dianggap mewakili item-item yang bersangkutan. Pengurutan berdasarkan item dengan nilai loading factor terbesar ditempatkan pada posisi teratas dimaksudkan untuk memudahkan pembaca. 
Tabel 11

Penamaan Faktor

\begin{tabular}{cc}
\hline Faktor & Nama Faktor \\
\hline I & Keluarga \\
\hline II & Kepribadian \\
\hline III & Pilihan Saluran Pembelian \\
\hline
\end{tabular}

(Sumber: Hasil Olahan Data Peneliti dengan SPSS, 2021)

Menurut (Soeroso, 2018) dalam melakukan penamaan terhadap faktor yang telah terbentuk, penulis memberikan cara pemberian nama berdasarkan pada variabel yang memiliki nilai loading factor tertinggi. Pemecahan masalah penelitian telah dijelaskan oleh ketiga faktor yang terbentuk adalah 58,015\% yang berarti ketiga faktor tersebut secara keseluruhan dapat menjawab 58,015\% dari masalah dalam penelitian. Sisanya sebesar $41,985 \%$ tidak dijelaskan dalam penelitian ini karena dianggap tidak berkontribusi secara signifikan.

\section{Kesimpulan}

Berdasarkan hasil pengolahan data terdapat tiga faktor baru yang terbentuk yang dapat mempengaruhi keputusan pembelian konsumen busana gamis wanita di Toko Baju AA. Dari tiga faktor yang terbentuk tersebut semuanya saling berkaitan satu sama lain terhadap keputusan pembelian konsumen. Faktor yang pertama adalah keluarga, kelas sosial, kebudayaan, kelompok referensi, dan jumlah pembelian. Faktor yang kedua adalah kepribadian, pengalaman belajar, persepsi, juga kepercayaan dan sikap. Faktor yang ketiga atau yang terakhir adalah pilihan saluran pembelian, pilihan produk, pilihan merek, dan motivasi. Faktor paling dominan yang mempengaruhi keputusan pembelian kosumen busana gamis wanita di Toko Baju AA dilihat dari nilai total variance explained yang di dapat dari proses analisis faktor. Dari ketiga faktor yang telah terbentuk, nilai total variance explained yang tertinggi adalah faktor pertama dengan item keluarga sebagai loading factor. Sehingga untuk faktor yang paling dominan dan mempengaruhi keputusan pembelian busana gamis wanita di Toko Baju AA adalah faktor Keluarga. Berdasarkan alasan dan pertimbangan dari penulis terkait dengan hasil penelitian berupa faktor yang paling dominan berupa faktor Keluarga dan melihat langsung pada kondisi di lokasi objek penelitian, faktor ini doniman dikarenakan banyaknya responden yang merupakan pelanggan dan beberapa rekanan yang sudah sering datang dan berbelanja pakaian di Toko Baju AA sehingga menimbulkan sisi kekeluargaan yang erat antara penjual dan juga pembeli yang menyebabkan faktor ini menjadi dominan dibandingkan dengan faktor-faktor lainnya. 
Analisis Faktor-Faktor yang Mempengaruhi Keputusan Pembelian Produk Busana Gamis Wanita pada Toko Baju AA Di Pasar Pemda Cikampek

\section{BIBLIOGRAFI}

Amin, Muhamad. (2016). Strategi Pemasaran Mlm (Multi Level Marketing) Perspektif Ekonomi Islam (Studi Kasus Pada Pt. Natural Nusantara Cabang Purwokerto). Iain Purwokerto. Google Scholar

Ansori, Haerun. (2019). Faktor Perilaku Konsumen Terhadap Keputusan Pembelian Busana Muslim Dan Muslimah Di Toko Atikah Collection123 Perumnas Kelurahan Tanjung Karang Permai Kecamatan Sekarbela Kota Mataram. Uin Mataram. Google Scholar

Aprilian, Yaswar. (2017). Pengaruh Faktor Kepribadian Konsumen Terhadap Keputusan Pembelian Pakaian Distro Di Tembilahan. Jurnal Analisis Manajemen, 3(1), 46-56. Google Scholar

Cresswell, J. W. (2017). Research Design: Pendekatan Kualitatif, Kuantitatif, Dan Mixed (Edisi Ketiga). Yogyakarta: Pustaka Belajar. Google Scholar

Eddy, M. Fahrul Ainul Yakin Pembimbing, \& Soegiarto, K. (2017). Perilaku Konsumen Dalam Berbelanja Pakaian Wanita Di Pasar Pagi Samarinda. Ekonomia, 5(3), 298-312. Google Scholar

Habli, Ahmad. (2020). Pengaruh Kualitas Produk Dan Harga Terhadap Minat Beli Konsumen Di Toko Ais Jaya Fashion Pekanbaru Menurut Perspektif Ekonomi Syariah. Universitas Islam Negeri Sultan Syarif Kasim Riau. Google Scholar

Hayati, Naima. (2012). Pengambilan Keputusan Beli Busana Muslim. Yogyakarta: Fakultas Syari'ah Dan Hukum, Uin Sunan Kalijaga. Google Scholar

Khasanah, Mualimatul. (2016). Faktor-Faktor Yang Mempengaruhi Konsumen Dalam Pengambilan Keputusan Pembelian Busana Muslim (Studi Kasus Pada Butik Muslim Sofie Fashion Semarang). Uin Walisongo. Google Scholar

Kotler, Philip Dan Keller, Kevin Lane. (2016). Marketing Management (16th Ed.; New Jersey, Ed.). Google Scholar

Kotler, P. (2016). Prinsip-Prinsip Pemasaran. Jakarta: PT. Rineka Cipta. Google Scholar

Kurniasih, Retno. (2018). Analisis Perilaku Konsumen Terhadap Produk Batik Tulias Banyumas. Jurnal Ekonomi, Bisnis, Dan Akuntansi, 20(1). Google Scholar

Puspitasari, Ratih, \& Mubarak, M. M. (2012). Perilaku Pembelian Produk Pakaian Bermerek Yang Dilakukan Staf Pengajar Stie Kesatuan Bogor. Jurnal Ilmiah Ranggagading (Jir), 12(1), 47-54. Google Scholar

Sangadji, E. M. (2018). Perilaku Konsumen Pendekatan Praktis. Yogyakarta: Andi Offset. Google Scholar 
Hanansa Rais Dabinda

Schiffman, L. (2010). Perilaku Konsumen. Jakarta: Macanan Jaya Cemerlang. Google Scholar

Soeroso, Santoso. (2018). Latihan Statistik Multivariat. Jakarta: Elex Media Komputindo. Google Scholar

Stanton, W. J. (2015). Prinsip Pemasaran (Edisi Ketu). Jakarta: Erlangga, Jakarta. Google Scholar

Tjahjono, Amelia. (2013). Analisa Marketing Mix, Lingkungan Sosial, Psikologi Terhadap Keputusan Pembelian Online Pakaian Wanita. Jurnal Strategi Pemasaran, 1(2), 1-9. Google Scholar

\section{Copyright holder:}

Hanansa Rais Dabinda (2021)

First publication right:

Syntax Literate: Jurnal Ilmiah Indonesia

This article is licensed under:

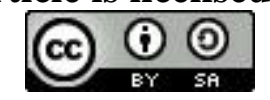

